\title{
COMMENTARY ON GREENE AND MAYR
}

The exchange between Greene and Mayr is a double pleasure to read because it represents a commentary about history by two men who have, through the excellence of their own works, helped to shape the history of evolutionary thought.

Yet I find that both men are talking largely past rather than to each other. Mayr writes to defend the specific mechanics of natural selection ; Greene is questioning the philosophical underpinnings of Darwin's world view.

Mayr, as the greatest living architect of the modern synthesis, presents a cogent and spirited defense of the theory that has been his life's work. A line near the end of his piece defines his position : Darwin was right about natural selection, and our modern understanding, particularly the integration of genetic knowledge with the work of field naturalists, has affirmed and extended his basic outline : "Where we differ from Darwin is almost entirely on matters of emphasis. "

Mayr views Greene's paper as a subtle attack upon the Darwinian mechanism. He epitomizes Greene's conclusion crisply, to say the least : "In other words, Darwin is dead ! " Mayr even ventures a speculation on Greene's motive for questioning Darwin : " It is evident that Greene is a devout Christian. Apparently he cannot adopt Darwinism because he sees God's hand in everything in nature."

I am not attracted by this attempt to reinstitute the notion that science and religion are locked in a struggle to the death. The simple, empirical fact that the ranks of Darwinian evolutionists have included devout atheists (J. B. S. Haldane), anticlerical rationalists (I would place Mayr here), and dedicated Christians (Mayr's greatest colleague Dobzhansky) should prove that the factual claims of natural selection do not specify any religious attitude. Indeed, just a few paragraphs after interpreting

Revue de synthèse : IV ${ }^{\bullet} \mathrm{S} . \mathrm{N}^{\circ} 3$, juillet-septembre 1986. 
Greene as seeking Darwin's death, Mayr gives us a hint that he does grasp the different level of Greene's major argument : "Greene might answer that he is not interested in technical details of evolutionary biology, but in the more basic conceptual framework that controlled Darwin's thinking. " This, I think, is an accurate statement of Greene's concerns. It also explains why much of Mayr's commentary does not directly join the issues that Greene raises.

As I understand Greene's major thesis - and it does treat philosophical underpinnings rather than the technical content of Darwinian theory - he argues that the Cartesian program (viewing current nature as derived from different past states under natural laws governing matter in motion) produced philosophical tension by suggesting concepts that fell into conflict with the mechanical cosmology from which it arose : progress, mind as a part of nature, struggle, chance and individuality, for example. Since Darwin accepted the mechanistic framework for nature's laws of motion, his deep-seated view of nature (by which I mean his ontology for the central character of things, not his consistent view of organisms per se) contained some inherent incoherence - for his commitment to the mechanical cosmology established an intrigue with stable predictability, while his statistical view of organic change produced a history of life that seemed full of quirks, oddities and even randomness.

Greene argues that this incoherence - perhaps internal conflict would be a better term - expresses itself most forcefully in Darwin's ambiguous views about the concept of progress, a notion supported (on the one hand) both by a general commitment to theories of change and by Darwin's particular social context, but questioned by both the statistics and chance in his own theory of change, and by the lingering appeal of a clocklike universe.

Yet Darwin was, ultimately, an eminent Victorian - and so, when forced to some decision, could not abandon his nation's and his century's belief in progress, Greene therefore, in a clever move of argument, switches his attention to twentieth-century Darwinians who might be expected to encounter the same dilemma about progress, but who would not have the social buttress of confident expansionism that led a Victorian like Darwin to his ultimate peace with such a concept. He wisely focuses upon Julian Huxley who engaged in a personal and explicit struggle with the notion of progress throughout his career. No other modern Darwinian has been so obsessed with the notion of progress.

Greene presses home his theme about the intrinsic incoherence of Darwinism's philosophical underpinning by arguing that Julian Huxley could not resolve the issue of progress in his twentieth-century context, 
and that he was eventually driven to an (at least implicit) vitalism and teleology quite out of keeping with the professed aims of his program. Greene then ends his argument with a final irony that probably inspired Mayr's ire and assumption (incorrect, I think, or at least without clear support from Greene) that Darwin's intellectual death is Greene's aim : Darwin's lingering commitment to the mechanical world view caused him enough trouble in his own day ; but the situation is worse now, since a range of physical findings, from quantum indeterminancy on, have cut the underpinnings of the mechanical view itself.

Thus, I view Greene's general argument, summarized above, as a statement that the philosophical underpinnings of Darwin's world view led at first to internal incoherence (in Darwin's own day, but exacerbated in modern thinkers like Julian Huxley), and then to actual invalidation under modern physics. But none of this is, as Mayr argues, a claim for the death of natural selection as a specific theory of evolutionary change. Scientists are often philosophically naive, crass or mistaken. Many true and powerful views have been supported for the silliest reasons, or under the flimsiest of general rationales.

Nonetheless, while I think that Mayr speaks past Greene (though making numerous valid and interesting points along the way), I am not happy with Greene's general argument in its own terms, and for two major reasons. First, I do not think that his two-pronged illustration of the deep dilemma faced by modern Darwinians is accurate (drive towards vitalism in resolving the paradox of progress, followed by collapse of the mechanical world view in general). I do not agree that Huxley was so driven into the hands of supposed philosophical enemies of Darwinian mechanics. I began my own career by investigating, at Huxley's suggestion, the subject that he had virtually invented : allometry, or the relationship of size and shape. I have studied Huxley's views on progress and their relationship with his general commitments. I deny that Huxley was driven to vitalism and teleology by his internal need (which I do affirm) to develop some intelligible notion of progress within Darwinism. Rather, he did what any good allometrician would do : he tried to define progress in biomechanical terms, in the arguments of engineering efficiency. This mechanistic view of progress lies at the base of his last great theoretical campaign within evolutionary theory : to devise an alternate system to replace genealogical diagrams (evolutionary trees) by bypassing time and plotting diversification (or cladogenesis) against progress (or anagenesis) defined biomechanically. He referred to these two concepts as clades and grades.

I also fail to see the force of whatever quantum indeterminacy has done to the mechanical world view, since these effects do not operate 
at the sizes and speeds of Darwinian objects (organisms and their struggles for reproductive success), where the Newtonian equations still reign.

Second, and here I very much agree with a theme that Mayr has urged throughout his career, I believe that, although Greene is correct in describing a tension between old-fashioned mechanism and the statistical and historical character of Darwin's theory, I would also hold that Greene is incorrect in arguing that such a tension makes Darwin's theory incoherent. Rather, Darwin thought the matter through and resolved it to his (and my) satisfaction. During the past two years, and after rereading the Darwinian corpus, I think that I have discerned the missing and coherent key behind all his works. Darwin was trying to establish the basis for a science of history that would depart from canons of experiment and prediction expected in the mechanical sciences. He recognized that history's complex pathways and constraints of heritage would supply irreducible uniqueness and nonpredictability to any lineage. Such a situation, Darwin argued, should not drive scientists to despair, but to the recognization that historical events require other canons and criteria for their resolution. Darwin gained both independence from the underpinnings of his scientific past, and coherence for his own view of nature, by respecting the different, but equally scientific character of complex historical sequences. I can offer no better illustration of Darwin's commitment and resolution than the famous closing lines of the Origin of Species, where Darwin explicitly contrasts the endless cycling of planets, going nowhere by the mechanical laws of matter in motion, with the continual newness of organic history, not for vitalistic or mystical reasons, but as a simple result of historical complexity and contingency :

" There is grandeur in this view of life... and that, whilst this planet has gone cycling on according to the fixed law of gravity, from so simple a beginning endless forms most beautiful and most wonderful have been, and are being, evolved. "

Stephen Jay Gould, Museum of Comparative Zoology, Harvard University. 